in the native protein have protected protons in the molten globule intermediate (J. Baum, personal communication).

But the mystery of the molten globule intermediates now gets darker. An important motivation for studying protein folding pathways is to find the principles that relate amino-acid sequence to threedimensional structure. Protein chemists have become used to thinking that the chief structure-determining principle is based on close packing of hydrophobic side chains in the protein core ${ }^{17}$, but the hydrophobic side chains are still exposed to water in the molten globule. What, then, determines that the helices that form in the molten globule of $\alpha$-lactalbumin are similar to those in the native protein?

As if these conundrums were not enough, Ptitsyn and co-workers ${ }^{18}$ have now added another. They propose first that molten globule intermediates occur universally on the kinetic pathway of protein folding and then present evidence suggesting that the molten globule is formed only after secondary structure appears, which contradicts the above suggestion that secondary structures are formed because the molten globule has a compact conformation. If a hydrophobic collapse is not needed to produce secondary structures in folding intermediates, then what does stabilize them? The trail seems to be leading back towards the framework model. It is a safe bet that new developments will come rapidly.

Robert L. Baldwin is in the Biochemistry Department, Stanford University, Stanford, California 94305, USA.

\title{
Ice masses on the move
}

\section{Donald G. Sutherland}

DURING the last glacial cycle (approximately 120,000 to 10,000 years ago) the maximum expansion of ice sheets is generally presumed to have occurred at around 18,000 years before present $(\mathrm{BP})$ : Glacial advances pre-dating this time are not well documented, apparently because of the destruction of evidence by that last ice advance as it over-rode the deposits of the earlier glaciations. The work of Seret et al., reported on page 453 of this issue ${ }^{1}$, is therefore of particular interest. They apparently demonstrate that at least one phase of glaciation of the Vosges mountains (at approximately $48^{\circ} \mathrm{N}$ ) during the last glacial cycle was considerably more extensive than that which occurred at the last glacial maximum. An extensive end moraine system that marks the maximum extent of the ice is reported, and dating control on the ice advance is derived from long sequences of terrestrial and lake sediments preserved in basins outside and inside the ice limits.

The interglacial/glacial/interglacial cycle of the past 125,000 years is important in elucidating the mechanisms controlling the Earth's climate. As it is the most recent such cycle, the relatively well preserved and geographically widespread deposits dating from it allow detailed reconstruction of particular events. The period offers examples of large, rapid changes in climate as at the end of the last cycle when global temperatures may have increased by around $5^{\circ} \mathrm{C}$ over a few centuries (or less). It is also possible to recreate the palaeogeography and palaeoclimate of certain periods characterized by climates markedly different from the present climate and to use these reconstructions to test computer models of global circulation.
The distribution of glacial ice is of great importance for palaeoclimatic modelling. Ice has a crucial effect in reflecting solar radiation: the largest ice sheets were of sufficient size to modify the general circulation. And individual ice masses also had direct effects on local climate, modifying, for example, precipitation patterns in their immediate vicinity. But although the general trends in climate during the last glacial cycle have been indicated by analyses of deep-sea sediments or ice cores from the Greenland and Antarctic ice sheets, these continuous records are unable, in other than a rather general way, to indicate the geographical expression of the environmental changes they record. Thus, for example, although it may be possible to infer that a certain volume of ice existed during a certain period, little can be deduced as to where that ice had accumulated. Similarly, rapid changes in temperature, whether positive or negative, can be inferred from the continuous records, but this tells little of the environmental response to these changes. It is necessary, therefore, to turn to the continental record to discover the evidence relevant for palaeogeographical reconstructions.

In their study ${ }^{1}$, Seret et al. describe a series of terminal moraines formed by an ice mass emanating from the Vosges mountains in France. They establish that these moraines are more than approximately 30,000 years old, from the sequence of sediments in the Cusenier basin which lies within the outermost limits of the ice advance. In addition, they use the long sequence of terrestrial environmental change interpreted from the sediments preserved in the neighbouring Grand Pile peat bog to suggest that the most probable period for the glaciation was between 30,000 and $50,000 \mathrm{BP}$. They do not rule out the possibility of earlier glaciation, however, nor, as the moraines marking the limit of the ice advance are multiple, the possibility that there was more than one period of glaciation.

Their favoured timing of the glaciation falls within oxygen-isotope stage 3 , a period some would consider relatively mild, although one in which the deep-sea record indicates there to have been substantial global ice volume. As noted by Seret et al., the southern margin of the Laurentide ice sheet was apparently well advanced during this period ${ }^{2}$ and comparison may also be made with the western Norwegian sequence ${ }^{3}$ where glaciation of the coast during the Skjonhelleren Stadial (between approximately 60,000 and $30,000 \mathrm{BP}$ ) has been inferred.

The dynamics of an ice mass is a question of balance between accumulation and ablation, the former generally being aided by increased solid precipitation and the latter largely being controlled by temperature. As the precise balance between these two major variables for a particular area may differ somewhat from one cold period to another then the dimensions of any consequent glacial build-up need not be similar in any two such periods. Seret et al. use evidence from minerals and pollen from the Grand Pile bog to address this problem and suggest that the principal local control on ice expansion and contraction in the Vosges was precipitation rather than temperature.

Thus they envisage the ice building up during a period of cool but not extremely cold climate, a period characterized by high snowfall and with the ice in retreat as much in response to a decrease in snowfall as to an increase in temperature. Although they do not directly state it, there is the further possible implication that a different combination of precipitation and temperature occurred during the build-up of the ice immediately before about $18,000 \mathrm{BP}$. This could explain the smaller ice mass that developed in the Vosges at the later time.

This work of Seret et al. highlights a current lack of knowledge about major ice masses during the last glacial cycle. With the broad temperature trends during this period already relatively well known, more work along these lines could yield a better idea of the contemporaneous changes in precipitation patterns. With that, we would have a nearcomplete picture of the glacial climate. $\square$

Donald G Sutherland is at Placer Analysis Ltd, 2 London Street, Edinburgh EH3 6NA, UK.

1. Seret, G., Dricot, E. \& Wansard, G. Nature 346, 453-456 (1990).

Dreimanis, A. Geol. Soc. Am. Centennial Field Guide. 345-346 (Geol. Soc. Am., Washington, 1987).

3. Larsen, E. \& Sejrup, H. P. Quat. Sci. Rev. 9, 85-97 (1990).

NATURE $\cdot$ VOL $346 \cdot 2$ AUGUST 1990 